\title{
Determination of volatile non intentionally added substances coming from a starch-based biopolymer intended for food contact by different gas chromatography-mass spectrometry approaches
}

\author{
Jazmín Osorio $^{\mathrm{a}}$, Nicola Dreolin ${ }^{\mathrm{b}}$, Margarita Aznar ${ }^{\mathrm{a}}$, Cristina Nerín ${ }^{\mathrm{a}, *}$, Peter Hancock ${ }^{\mathrm{b}}$ \\ a Analytical Chemistry Department, GUIA Group, I3A, EINA, University of Zaragoza, Ma de Luna 3, 50018, Zaragoza, Spain \\ ${ }^{\mathrm{b}}$ Waters Corporation, Wilmslow, SK9 4AX, United Kingdom
}

\section{A R T I C L E I N F O}

\section{Article history:}

Received 18 January 2019

Received in revised form 29 March 2019

Accepted 3 April 2019

Available online $\mathrm{xxx}$

\section{Keywords:}

Starch-based biopolymers

APGC-Q/ToF

Migration

NIAS

Food contact material

\begin{abstract}
A B S T R A C T
The rapid growth of polymer technology in the field of food contact materials (FCMs) needs to be supported by continuous improvement in material testing, in order to ensure the safety of foodstuff. In this work, a range of different starch-based biopolymer samples, in the shape of pellets and retail samples (cups and dishes) were studied. The optimized extraction process was performed on three different pellet shapes: pellets with no modification (spherical), pellets shattered under high pressure (lentils), and pellets cryogenically ground (powder). The analysis of unknown volatile and semi-volatile compounds was carried out by gas chromatography-mass spectrometry, using both electron ionization with a single quadrupole mass analyzer (GC-EI-MS), and atmospheric pressure gas chromatography with a quadrupole/time of flight mass analyzer (APGC-Q/ToF). The identification process was implemented using the latest advances in the understanding of APGC ionization pathways. Chemical migration was also assessed on prototype samples using the food simulants: ethanol $10 \% \mathrm{v} / \mathrm{v}$, acetic acid $3 \% \mathrm{w} / \mathrm{V}$, ethanol $95 \% \mathrm{v} / \mathrm{v}$, isooctane, and vegetable oil. Each migration test was performed three consecutive times, as recommended for materials intended for repeated use.
\end{abstract}

(C) 2019 Published by Elsevier B.V.

\section{Introduction}

A number of surveys concerning starch as a principal raw material for the production of biodegradable plastics are in progress. Due to its renewability, cheapness, and physical properties, starch has been embraced by the food industry to be employed as a food contact material [1-3]. Today, thermoplastic-like starch (TPS), together with polylactic acid (PLA), are the main research routes for the manufacturing of biodegradable materials [4]. Starch itself is not thermoplastic, but in the presence of plasticizers and reagents with hydrophilic character, high temperatures $\left(90-180^{\circ} \mathrm{C}\right)$ and shearing, it melts and fluidizes, enabling its use in injection, extrusion and blowing equipment, such as those used for synthetic plastics

Abbreviations: TPS, thermoplastic-like starch; PLA, polylactic acid; LDPE, low density polyethylene; FCMs, food contact materials; NIAS, non-intentionally added substances; GC, gas chromatography; EI, electron ionization; MS, mass spectrometry; APGC, atmospheric pressure gas chromatography; HRMS, high resolution mass spectrometry; $\mathrm{APCI}$, atmospheric pressure chemical ionization; $\mathrm{Q}$ quadrupole; ToF, time of flight.

* Corresponding author.

E-mail address: cnerin@unizar.es (C. Nerín).
[5]. Environmental pollution and disposal problems of traditional packaging materials, can be overcome by TPS films, which are made mainly from starch finished with different thermoplastic polyesters [6].

Nevertheless, the components in polymer packaging materials are not completely inert. Several studies have warned about potential toxic effects of some packaging components such as bisphenol A or phthalates (endocrine-disrupting chemicals) in plastic toys and in cosmetics in contact with plastic packaging $[7,8]$. A correlation between the use of some multilayer plastic bags for artificial insemination has also been correlated to reproductive failures [9]. In the case of packaging intended for food contact, plastic components can migrate into the food. This mass transfer is considered as a potential source of pollution because the migrants could alter the food composition, deteriorate the organoleptic properties, and even incur a human health risk [10-17].

The rapid growth of polymer technology in the field of food contact materials (FCMs) needs to be sustained by continuous improvement in material testing, in order to ensure the safety of foodstuff [18]. High resolution mass spectrometry is one of the most powerful tools when dealing with the analysis of NonIntentionally Added Substances (NIAS), which are defined in the 
European Union (EU) Regulation No 10/2011 [19] as “impurities in the substances used, or reaction intermediates formed during the production process or decomposition or reaction products". It is not surprising that these substances have been recognised as a major challenge in material suitability testing, since the main concern about NIAS is the lack of toxicological data to be used for determining a specific migration limit $[18,20]$. The main reasons that make the identification process remarkably complex and time-consuming are the increasing complexity of materials and the absence of commercial standards for structure confirmation. Furthermore, there is a consistent lack of information about the real composition of the different ingredients and materials employed for polymer manufacturing, as the material composition is usually strictly confidential.

Before performing a migration study, a screening analysis of the packaging material is often required to identify the chemicals that are more likely to migrate into the food. Particular emphasis should be given to NIAS having a molecular weight below $1000 \mathrm{Da}$, since it is generally recognized [21] that heavier compounds have lower diffusion coefficients. Migration tests are run under specific conditions of time and temperature, selecting the food simulants according to the intended use of the material [22-24].

With respect to semi-volatile and volatiles analyses, a GC coupled to a quadrupole mass spectrometer equipped with electron ionization (EI) using $70 \mathrm{eV}$ is typically employed (GC-EI-MS), since this ion source is fairly capable of ionizing virtually any organic compound in a robust and reproducible way, and it allows the analyst to make use of scientific libraries for comparing acquired spectra with references [25]. However, the identification process becomes almost impossible when the compound of interest is not listed in the library, or when the sensitivity of the single quadrupole MS is not sufficient for reliable mass confirmation. At this stage, atmospheric pressure gas chromatography (APGC) coupled to high resolution mass spectrometry (HRMS) can become an interesting alternative to traditional GC-EI-MS [25-29]. APGC is a "soft" ionization technique, similar in nature to atmospheric pressure chemical ionization (APCI). With respect to Chemical Ionisation (CI), APGC offers the advantage of simplicity and flexibility, as the ionisation would take place even in the absence of a chemical modifier, such as methane and ammonia, commonly employed in CI. Furthermore, APGC is compatible with higher carrier gas flow rates, and there is no need of breaking the vacuum when general maintenance of the ion source is required. In literature, two main ionization processes have been described for APGC in some detail [30-34]. In brief, ionization is affected by the source environmental conditions. When operating under "dry" conditions, the high make-up and auxiliary gas flow rates provide substantial amounts of nitrogen, which determines the formation of a nitrogen plasma. Radical cation species react with the analytes via charge transfer, and give rise to the $\mathrm{M}^{+}$molecular ion. Alternatively, ionization can take place indirectly through proton transfer reactions, forming $[\mathrm{M}+\mathrm{H}]^{+}$ ions. Protonation is enhanced when an excess of water or other modifiers are present in the system. In essence, the analyte proton affinity, or gas phase basicity, determines if the modifier will facilitate or suppress the protonation reactions. By opportunely setting the gases flow in the source, it is also possible to run the instrument in a mixed mode configuration, where both charge transfer and protonation are observed. However, this will result in a compromise in sensitivity for both forms of ionization. The chemical structure of the target molecules can provide useful insight on the most suitable configuration for the analysis.

The work herein aims to determine the main volatile NIAS coming from a novel starch-based biopolymer and to explore new applications of APGC in support of GC-EI-MS, by means of using the latest discoveries in the APGC ionization. The potential new ionization processes, such as the multi-adduct formation, will be used in order to increase the confidence in the structure elucidation of the unknown compounds. In addition, specific migration assays were carried out, in order to check the compliance of some prototype samples to European legislation.

\section{Materials and methods}

\subsection{Chemicals and reagents}

Ethylhexyl adipate 99\% (CAS: 103-23-1), diethyl phthalate >99\% (CAS: 84-66-2), bis (2ethylhexyl) sebacate 97\% (CAS: 122-623), 1,4-trioxa- cyclotridecane-8,13-dione (CAS: 1675-54-3) 98\%, 11-eicosenamide 98\% (CAS: 10586-57-9), isopropyl palmitate 90\% (CAS: 142-91-6), palmitamide 99\% (CAS: 629-54-9), octadecanamide $85 \%$ (CAS: 124-26-5), hexachlorobenzene 99\% (CAS: 118-74-1), adiponitrile 99\% (CAS: 111-69-3), furfural 99\% (CAS: 98-01-1), methyl palmitate $>99 \%$ (CAS: 112-39-0), dipropyl phthalate $98 \%$ (CAS: 131-16-8), and furaneol >99\% (CAS: 3658-77-3) were purchased from Sigma-Aldrich (Madrid, Spain). Docosanoic acid ethyl ester 99\% (CAS: 5908-87-2) was supplied by LGC Standards (Barcelona, Spain). Ethanol absolute (HPLC grade), methanol (LC-MS grade), acetic acid, dichloromethane, toluene, dimethyl sulfoxide, and isooctane (HPLC grade) were supplied by Scharlau (Setmenat, Spain). Hexane was from Fischer Chemicals (UK). Ultrapure water was generated by a Millipore Milli-Q system (Billerica, MA, USA). Commercial sunflower oil was used for the migration assays. The nitrogen evaporator was a TECHNE sample concentrator (Cole-Parmer Ltd., UK). The ultrasonic generator was a Branson 3510 (frequency applied $40 \mathrm{~Hz}$ ).

\subsection{Sample characteristics}

Biopolymers based on starch and polylactic acid (PLA) were supplied by a polymer manufacturing company for this study. The company is protected by a non-disclosure agreement and additional information about the sample can not be provided. The samples were provided in three different forms: raw starch (powder), pellets of two different compositions, and prototypes of retail samples (cups and dishes).

\subsection{Analysis by GC-EI-MS}

Analyses were carried out on a GC system (Agilent 7890 N, Santa Clara, CA, USA) equipped with an electron ionization (EI) ion source operating at $70 \mathrm{eV}$, and coupled with a quadrupole mass spectrometry detector (5977D, Agilent) operating in SCAN mode (scan range 50-450 m/z). The autosampler was a Combi PAL (CTC Analytics, Zwingen, Switzerland). The chromatographic separation was performed on a HP-5MS column of $30 \mathrm{~m} \times 0.25 \mathrm{~mm}$ i.d. $x 0.25 \mu \mathrm{m}$ film thickness, injecting $1 \mu \mathrm{L}$ at $250^{\circ} \mathrm{C}$ in splitless mode. The oven temperature program was: $50^{\circ} \mathrm{C}$ held for $5 \mathrm{~min}$, ramp $10^{\circ} \mathrm{C} / \mathrm{min}$ to $300^{\circ} \mathrm{C}$ and held for $5 \mathrm{~min}$, with $4 \mathrm{~min}$ solvent delay. Helium was used as carrier gas at a constant flow of $1 \mathrm{~mL} \mathrm{~min}^{-1}$. The transfer line heater was set at $280^{\circ} \mathrm{C}$.

\subsection{Analysis by APGC-Q/ToF}

In parallel, analyses were performed using a 7890 A GC system (Agilent, Santa Clara, CA, USA) equipped with an Agilent 7683B autosampler, and coupled to a hybrid quadrupole/time-of-flight mass spectrometer (Xevo G2-XS QToF, Waters Corporation, Manchester, UK), operating in sensitivity mode in order to enhance ion signal, thus sensitivity of the system. The chromatographic separation was performed on a DB-5MS capillary column, $30 \mathrm{~m} \times 0.25 \mathrm{~mm}$ i.d. $\times 0.25 \mu \mathrm{m}$ film thickness. The oven temperature program was: $50{ }^{\circ} \mathrm{C}$ for $2 \mathrm{~min}, 10^{\circ} \mathrm{C} / \mathrm{min}$ ramp to $300^{\circ} \mathrm{C}$ and held for $10 \mathrm{~min} .1 \mu \mathrm{L}$ 
was injected in pulsed splitless mode at $250^{\circ} \mathrm{C}$ (pulse time $1.2 \mathrm{~min}$, pulsed pressure $32 \mathrm{psi}$ ). Helium was used as carrier gas at a constant flow of $1 \mathrm{~mL} \mathrm{~min}^{-1}$.

The ion source was operating in APCI + mode, with a Corona current of $2.2 \mu \mathrm{A}$. The sampling and extraction cone voltages were 30 and $3 \mathrm{~V}$, respectively. The cone and auxiliary gas flows were 140 and $225 \mathrm{~L} / \mathrm{h}$, respectively. The make-up gas was $\mathrm{N}_{2}$ at $300 \mathrm{~mL} \mathrm{~min}^{-1}$ and $300^{\circ} \mathrm{C}$, while the source temperature was $150^{\circ} \mathrm{C}$. When operating

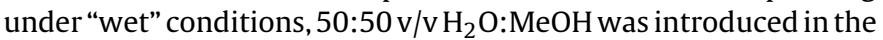
ion source as chemical modifier and the cone gas flow decreased to $50 \mathrm{~L} / \mathrm{h} .100 \mathrm{pg} / \mu \mathrm{L}$ solution of hexachlorobenzene (HCB) in hexane was used for installation checks, and for monitoring the source environmental conditions. The acquisition was performed in $\mathrm{MS}^{\mathrm{E}}$ mode, maintaining $6 \mathrm{eV}$ collision energy in function 1 , while a collision energy ramp 20-30 eV was used in function 2 . The scan time was $0.5 \mathrm{~s}$, and the acquisition range was $50-650 \mathrm{~m} / \mathrm{z}$. Sodium formate was used for routine mass calibration, whilst real-time mass correction was performed using a persistent column bleed peak (lock-mass $207.0324 \mathrm{~m} / z, \mathrm{C}_{5} \mathrm{H}_{15} \mathrm{O}_{3} \mathrm{Si}_{3}$ ).

\subsection{Data processing}

Data generated by GC-EI-MS were acquired and processed with MSD ChemStation software (v. F.01.03, Agilent). Library search was performed on NIST Standard Reference Database (2018), where only Match Values greater than 700 were considered. APGC-Q/ToF data were acquired and processed using UNIFI Scientific Information System (Waters Corporation). The general screening approach for the analysis of NIAS is described elsewhere [20], and was opportunely implemented here. Where possible, unidentified peaks in EI were submitted for an accurate mass analysis of the related molecular ions and their adducts on APGC, keeping the maximum mass error threshold at $2 \mathrm{mDa}$. Binary Compare feature of UNIFI was used to locate the components coming from the actual sample, by a direct comparison to the extracted blank sample data. In this way it was possible to trace also the compounds not visible in the total ion chromatogram (TIC). The Elucidation toolset of UNIFI was used to obtain in silico fragmentation of the most significant candidates after a screening check of the ChemSpider database. When feasible, the candidates where confirmed by standard injection under the same analytical conditions.

A confidence level was attributed to each candidate. Compounds presenting a NIST Match Value above 700, and supported by the accurate mass of the molecular ion and it's adducts (when possible) were labelled as Tentative. In addition to the previous conditions, compounds showing fragmentation pathways described by in-silico fragmentation, or by the analyst's expertise, were labelled as Confident. Compounds whose retention time and mass spectra match those of an authentic standard, were labelled as Confirmed. Finally, compounds that did not fulfil any of the previous conditions were labelled as Unknown.

\subsection{Sample extraction protocol}

First, pellet samples were crushed to obtain flat lentils, $0.5 \mathrm{~g}$ of lentils were extracted three times with $2.5 \mathrm{~mL}$ of methanol in an ultrasonic bath at $40^{\circ} \mathrm{C}$ for $1 \mathrm{~h}$. The total extraction solution $(7.5 \mathrm{~mL})$ was concentrated to $1 \mathrm{~mL}$ under a gentle nitrogen flow at room temperature before injection. For consistency, each sample and solvent blank were extracted and analysed in triplicate.

\subsection{Migration assays}

The migration assays were carried out on prototype samples (cups) in accordance with the European legislation on food contact materials (Regulation No 10/2011/EU) [19]. Two migration

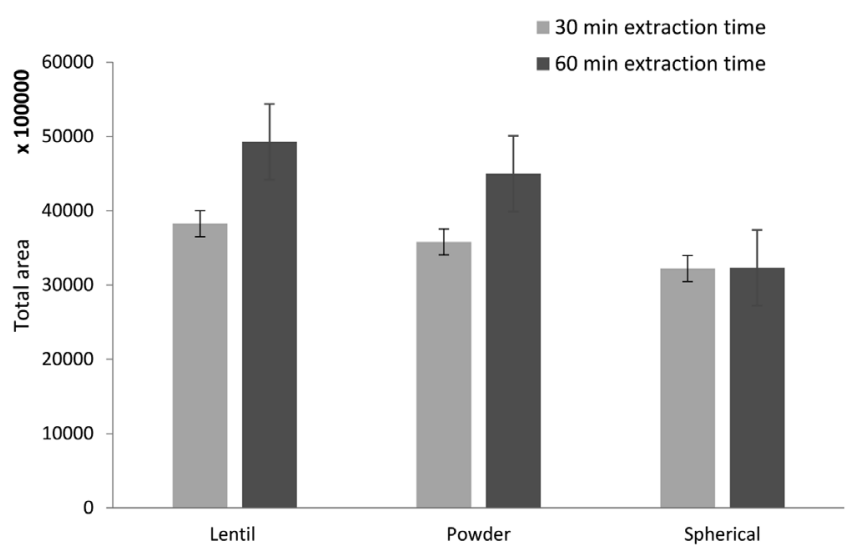

Fig. 1. Total peaks area of the compounds detected by GC-EI-MS of the extracted samples obtained from three forms of pellet (spherical, lentils and powder) at two extraction times, 30 and $60 \mathrm{~min}$. Error bars representing standard deviation.

assays were performed: overall migration and specific migration. In overall migration the objective is to ensure that food contact materials will not bring about an unacceptable change in the composition of the food. For this purpose, overall migration values must be, according to EU legislation, below $60 \mathrm{mg} \mathrm{kg}^{-1}$. Overall migration is the measurement of the total mass transferred from the FCM during the exposure to a food simulant. It was assessed with ethanol $10 \%(\mathrm{v} / \mathrm{v})$, acetic acid $3 \%(\mathrm{w} / \mathrm{V})$, ethanol 95\% (v/v), isooctane, and sunflower oil, at $70^{\circ} \mathrm{C}$ for $2 \mathrm{~h}$. In specific migration, the amount of every single component that migrates from the food contact material is evaluated, and these values should be below the specific migration values (SMLs) established in the EU legislation. Specific migration was assessed with ethanol $10 \%(v / v)$, acetic acid 3\% (w/V) and ethanol 95\% (v/v). Contact time and temperature were $6 \mathrm{~h}$ and $70^{\circ} \mathrm{C}$, respectively. In both cases migration test wereperformed by single-side contact, filling the cups with the corresponding simulants. Since the FCMs under study are intended for repeated use, the migration tests were performed three consecutive times [19]. The experiments were carried out in a thermostatic oven. The tests were performed in triplicate for each sample and blank. After migration, the detected analytes were semi-quantified against an external calibration, by using a range of standard compounds diluted in methanol. GC-EI-MS was used for quantitation purposes.

An experimental diagram of the analytical protocol has been designed (Supplementary 1).

\section{Results and discussion}

\subsection{Optimization of solvent extraction}

Different solvents were tested, but some of them such as dichloromethane, hexane, toluene or dimethyl sulfoxide seemed to dissolve the polymer. For this reason, methanol was selected as the final extraction solvent. The extraction was tested on the original pellet samples (spherical) and after submitting them to a mechanical transformation such as crushing (lentils) or grinding (powder). The aim was to check if an increase of the contact area improved the extraction efficiency. According to the results, a more efficient extraction of the compounds was achieved with lentils as well as with powder (Fig. 1). Since extraction efficiency was similar in both cases, lentils were selected since the extraction process was easier to handle. Two extraction times were evaluated: $30 \mathrm{~min}$ and $60 \mathrm{~min}$. The maximum total area of the peaks was obtained with 60 min of extraction (Fig. 1). 


\subsection{Advances in APGC ionization pathways}

Even though charge transfer and protonation are considered the prevalent ionization pathways in APGC, in this work potential new ionization processes that appeared to be dependent on the source environment were investigated. Generally, GC-APCI is well known to generate molecular weight diagnostic $\mathrm{M}^{+}$and $[\mathrm{M}+\mathrm{H}]^{+}$ ions $[35,36]$. However, a few studies demonstrated that in ambient corona discharge, the addition of $\mathrm{N}$ and $\mathrm{O}$ to hydrocarbons via ion/molecule reactions is possible [37]. In this work, we carried out an ionization experiment by injecting individual $100 \mathrm{pg} / \mu \mathrm{L}$ methanolic solutions of adiponitrile, furfural, methyl palmitate, and dipropyl phthalate into the APGC-Q/ToF system, under the instrumental conditions detailed in chapter 2.4. In addition to $\mathrm{M}^{+}$, $[\mathrm{M}+\mathrm{H}]^{+}$and $[\mathrm{M}-\mathrm{H}]^{+}$, it appeared that adiponitrile, furfural and methyl palmitate present the common adduct $\left[\mathrm{M}+\mathrm{CH}_{3}\right]^{+}$, whilst the dipropyl phthalate spectrum showed the ions $[\mathrm{M}+\mathrm{N}]^{+},[\mathrm{M}+\mathrm{O}]^{+}$, $[\mathrm{M}+\mathrm{NO}]^{+}$and $[\mathrm{M}+\mathrm{H}+\mathrm{NO}]^{+}$(Supplementary 2 ). Nitrogen atom insertion into a $\mathrm{C}-\mathrm{C}$ molecule backbone was reported by Li et al. [38] as taking place in field-assisted ionization. Somewhat related plasmainduced ambient reactions can occur in the APGC source, where the voltage applied to the corona pin can give rise to $\mathrm{N}_{3}{ }^{+}, \mathrm{N}_{2}{ }^{+}$; and $\mathrm{N}_{4}{ }^{+}$; which might then react with the analyte molecules, forming the kinetically favored nitrenium ions $[\mathrm{M}+\mathrm{N}]^{+}$and iminium cations $[\mathrm{M}+\mathrm{N}-\mathrm{H}]^{+}$(thermodynamic product) by neutral hydride loss. As a matter of fact, a certain level of moisture is always present in the ambient ionization chamber. When ionization takes place in a nitrogen atmosphere with traces of oxygen at low corona current, nitrogen addition is strongly favored over oxygen addition. At higher currents, the opposite is true [37]. Oxygen is known to produce ozone in corona discharges [39] and is likely responsible for the oxidation processes, including dipolar insertion and protonation to $[\mathrm{M}+3 \mathrm{O}+\mathrm{H}]^{+}$, and sequential loss of one or two molecules of water, obtaining $[\mathrm{M}+2 \mathrm{O}-\mathrm{H}]^{+}$and $[\mathrm{M}+\mathrm{O}-3 \mathrm{H}]^{+}$. The $[\mathrm{M}-\mathrm{H}+\mathrm{O}]^{+}$species can be associated with $\mathrm{O}-\mathrm{O}$ bond cleavage and rearrangement to generate ketones or $\mathrm{C}-\mathrm{C}$ bond heterolysis resulting in smaller chain aldehydes [37]. In the proximity of the corona discharge needle, the $\mathrm{NO}^{+}$species can form [40] and react with the analyte molecules to give $[\mathrm{M}+\mathrm{NO}]^{+}$ions. As well as water and dioxygen, the ambient ionization chamber can also contain hydrocarbons in a lesser extent, which might lead to the formation of $\left[\mathrm{M}+\mathrm{CH}_{3}\right]^{+}$ions. These processes are determined by the atmospheric composition of the ion source, gases flow rate, corona pin position with respect to the sampling cone orifice, and by the chemical structure and reactivity of the target molecule.

\subsection{Identification of NIAS present in a starch-based biopolymer}

The recent advances in the understanding of APGC ionization were used for identification purposes. After the optimized extraction of the polymer, a total of 21 compounds were detected. Glycerol, tetradecanoic acid, ethyl ester, 2-palmitoglycerol, and 9,12-octadecadienoic acid, methyl ester were only detected with EI; whilst tris(2,4-ditert-butylphenyl)phosphite and the unknown peaks at 26.2 , and $28.8 \mathrm{~min}$ where detected by APGC exclusively. This occurrence is further evidence that the two ionization techniques are complementary for non-targeted analysis [32,41]. Table 1 shows the accurate mass of the most abundant adducts in APGC, retention times, and molecular formulae.

Some of the identified compounds might come from the degradation of the material, which is caused by oxidation reactions taking place at the surface of the polymer in contact with air and moisture. These radical reactions involve the formation of hydroporoxyl species, which will then undergo $\beta$-cleavage and fragmentation, rearrangement, and cyclization, leading to secondary products,

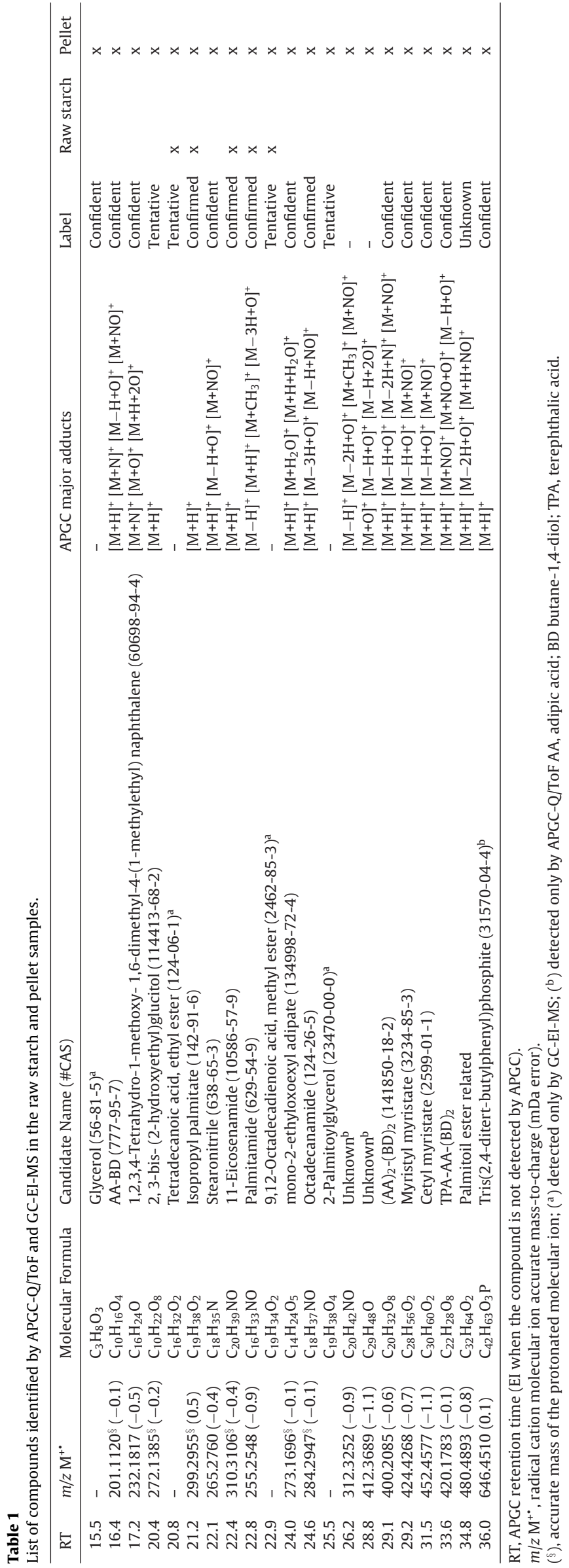


Table 2

Results of specific migration from the prototype samples to ethanol 95\% (V/V), expressed as mg of analyte per kg of food simulant ( \pm standard deviation).

\begin{tabular}{|c|c|c|c|c|c|c|c|}
\hline \multirow{2}{*}{ RT } & \multirow{2}{*}{ Candidate } & \multirow{2}{*}{ \# CAS } & \multirow{2}{*}{ Cramer Class } & \multicolumn{3}{|c|}{ Specific migration $\left(\mathrm{mg} \mathrm{kg}^{-1}\right)$} & \multirow{2}{*}{$\begin{array}{l}\text { Quantitation } \\
\text { Standard }\end{array}$} \\
\hline & & & & First & Second & Third & \\
\hline 11.4 & 2-Acetyl-2,3,5,6-tetrahydro-1,4-thiazine (M1) & $958999-62-7$ & III & $31.08 \pm 0.97$ & $16.51 \pm 1.50$ & $10.20 \pm 0.80$ & $\mathrm{e}$ \\
\hline 15.3 & $\mathrm{AA}-\mathrm{BD}$ & $777-95-7$ & I & $2.77 \pm 0.15$ & $1.30 \pm 0.07$ & $1.00 \pm 0.1$ & $\mathrm{e}$ \\
\hline 19.1 & Docosanoic acid, ethyl ester & $5908-87-2$ & I & $1.55 \pm 0.05$ & $1.17 \pm 0.13$ & $<0.60$ & $\mathrm{~d}$ \\
\hline 19.5 & 1,4-Benzenedicarboxylic acid, diethyl ester & $636-09-9$ & I & $<1.63$ & $<0.53$ & $<0.53$ & $\mathrm{~b}$ \\
\hline 20.8 & 4-hydroxy-3,5-dimethyl-2-Furanone (M2) & $22621-29-0$ & III & $27.31 \pm 1.63$ & $18.29 \pm 2.20$ & $16.03 \pm 2.56$ & $\mathrm{f}$ \\
\hline 24.5 & Hexadecanoic acid, dodecyl ester & $42232-29-1$ & I & $<0.57$ & $<0.57$ & $<0.19$ & $\mathrm{a}$ \\
\hline 24.8 & Hexadecanoic acid, octadecyl ester & 2598-99-4 & I & $1.93 \pm 0.30$ & $<0.57$ & $<0.57$ & $\mathrm{a}$ \\
\hline 25.2 & Hexadecanoic acid, hexadecyl ester & $540-10-3$ & I & $0.68 \pm 0.12$ & $<0.57$ & $<0.19$ & $\mathrm{a}$ \\
\hline 26.9 & Tetradecanoic acid, dodecyl ester & $2040-64-4$ & I & $<2.58$ & $<2.58$ & $<2.58$ & $\mathrm{c}$ \\
\hline 27.6 & $(\mathrm{AA})_{2}-(\mathrm{BD})_{2}$ & $141850-18-2$ & I & $<0.81$ & $<0.27$ & $<0.81$ & $\mathrm{e}$ \\
\hline 28.2 & Myristyl myristate & $3234-85-3$ & I & $8.28 \pm 0.29$ & $2.82 \pm 0.14$ & $<2.58$ & $\mathrm{c}$ \\
\hline 29.5 & Tetradecanoic acid, hexadecyl ester (M3) & 2599-01-1 & I & $18.76 \pm 0.95$ & $7.17 \pm 0.42$ & $6.34 \pm 1.36$ & c \\
\hline 29.9 & TPA-AA-(BD $)_{2}$ & - & III & $0.77 \pm 0.02$ & $0.36 \pm 0.02$ & $<0.27$ & $\mathrm{e}$ \\
\hline 30.7 & Hexadecanoic acid, hexadecyl ester (M4) & $540-10-3$ & I & $14.92 \pm 0.61$ & $4.53 \pm 0.31$ & $3.33 \pm 0.40$ & $\mathrm{a}$ \\
\hline
\end{tabular}

RT, retention time

M 1-4: Compounds with the highest migration values.

a: ethylhexyl adipate; b: diethyl phthalate; c: bis(2-ethylhexyl) sebacate; d: docosanoic acid ethyl ester; e: 1,4-trioxa- cyclotridecane-8,13-dione; f: furaneol.

AA: adipic acid; BD: butane-1,4-diol; TPA: terephthalic acid.

such as alcohols and carbonyl compounds with lower molecular weight (MW) [42]. These compounds further promoted the formation of lactones and furanones [43,44], such as 4-hydroxy3,5-dimethyl-2-furanone, detected after migration to ethanol 95\% (Table 2). Polymer manufacturers are very conscious of the issues that oxidation generates. Therefore, the intentional addition of authorised antioxidants to the polymer is a common procedure. Indeed, in the pellet samples tested, the antioxidant tris(2,4-ditertbutylphenyl)phosphite, also called Irgafos 168 [38], was detected at the very end of the chromatogram via APGC.

The addition of lubricants in starch-based biopolymers is a common practice. A typical lubricant is soybean oil, which is mainly composed of fatty acids, such as myristic and palmitic acids $[1,20,45,46]$. In Table 1 , it can be observed that nine of the identified compounds are myristic and palmitic acid derivatives. Esters could be formed by the reaction between fatty acids and alcohols coming from material degradation. Eicosenamide, palmitamide, and octadecanamide were also detected in the methanol extract, which might be intentionally added as slip agents $[47,48]$ for reducing the friction coefficient of the material. In the first half of the chromatogram, clusters of small and broad peaks were detected. By the analysis of the EI spectra, the most abundant fragment ions were indicative of polyalcohols. However, the low response in both EI and APGC did not allow us to reliably identify such components. At $15.5 \mathrm{~min}$, a high fronting-peak was identified as glycerol in EI. The high concentration of glycerol can be explained by its function as the principal plasticizer. Other potential plasticizers detected were 2,3-bis-(2-hydroxyethyl)glucitol and MEOHA (mono-2-ethyloxoexyl adipate). It is worth noting that MEOHA can be considered a proper NIAS, as it was found to be an oxidative metabolite of DEHA (2-ethylexyl adipate), which is widely used as a plasticizer for food contact plastics [49].

Three oligomers were also identified: [AA-BD], [(AA) $\left.)_{2}-(B D)_{2}\right]$, and [TPA-AA- $(\mathrm{BD})_{2}$ ] (where AA: adipic acid; BD: butane-1,4-diol; and TPA: terephthalic acid). These compounds were found to be degradation products of polymeric resins [45]. According to Canellas et al. [50], [AA-BD] and [(AA) $\left.)_{2}(\mathrm{BD})_{2}\right]$ can also lead to the formation of high MW cyclic oligomers and lactones. [TPA$\left.\mathrm{AA}-(\mathrm{BD})_{2}\right]$ could come from the degradation of the copolymer polybutylene adipate terephthalate (PBAT), which is commonly used in the manufacture of starch-based materials in order to increase its mechanical and barrier properties [51,52]. In Fig. 2, the APGC mass spectrum of [TPA-AA-(BD $)_{2}$ ] is shown, highlighting principal fragments and adducts under "dry conditions".

\subsection{Migration study}

Overall migration from the cup samples was $5.9 \pm 2.6 \mathrm{mg} \mathrm{kg}^{-1}$ in ethanol $10 \%$; $23.5 \pm 2.6 \mathrm{mg} \mathrm{kg}^{-1}$ in acetic acid $3 \%$; and $26.5 \pm 3.1 \mathrm{mg}$ $\mathrm{kg}^{-1}$ in sunflower oil. At the end of the overall migration experiment, physical changes were not observed in any of the samples. The results showed that overall migration was below the Overall Migration Limit (OML) of $60 \mathrm{mg} \mathrm{kg}^{-1}$, established by Regulation EU No 10/2011 [19] for the simulants tested and therefore the material fulfilled the requirements. Overall migration was also performed in vegetal oil substitutes, ethanol 95\%, and isooctane. However, they seemed to overestimate the overall migration with migration values above $60 \mathrm{mg} \mathrm{kg}^{-1}\left(100.0 \pm 5.1 \mathrm{mg} \mathrm{kg}^{-1}\right.$ and $143.4 \pm 15.6 \mathrm{mg}$ $\mathrm{kg}^{-1}$ respectively). The main reason is that probably isoctane and ethanol 95\% interact with the biopolymer and partially dissolve it, providing a higher mass transferred during the test.

With regards to specific migration tests, no compounds were detected in ethanol $10 \%$ and acetic acid 3\%. By contrast, 14 different compounds were found in ethanol 95\%. Among them, four were previously detected in the pellet samples. Table 2 shows the concentrations of the detected analytes in ethanol 95\% after each migration test. They were quantified by external calibration using the indicated standard compounds. All the standards showed good linearity with $\mathrm{R}^{2}$ greater than 0.987 and limits of detection (LODs) between 0.19 and $5.55 \mathrm{mg} \mathrm{kg}^{-1}$ (Supplementary 3).

The legislation states that compounds migrating from the material to the food should not pose a risk to human health [53]. After cross-checking the EU positive list of Regulation No $10 / 2011 / \mathrm{EU}$ [19], the identified compounds appeared not to be listed molecules. Therefore, the Cramer rules were applied to each compound for a theoretical evaluation of toxicity [54]. The toxicity level is established according to the molecular structure of the compound evaluated. The compounds can be classified within one of three different categories: class I (low toxicity), class II (medium toxicity), class III (high toxicity). Three compounds, 2-Acetyl-2,3,5,6-tetrahydro-1,4-thiazine, TPA-AA-(BD) 2 and 4-hydroxy-3,5-dimethyl-2-furanone, were found to be Class III-substances. The maximum concentration was found for 2Acetyl-2,3,5,6-tetrahydro-1,4-thiazine $\left(31.08 \pm 0.97 \mathrm{mg} \mathrm{kg}^{-1}\right)$. All other identified compounds were found to be Class I, obtaining tetradecanoic acid, hexadecyl ester the maximum concentration value $\left(18.76 \pm 0.95 \mathrm{mg} \mathrm{kg}^{-1}\right)$. According to the Threshold of Toxicological Concern (TTC) concept, depending on the Cramer class group of a compound, a maximum daily intake (TTC value) can be 

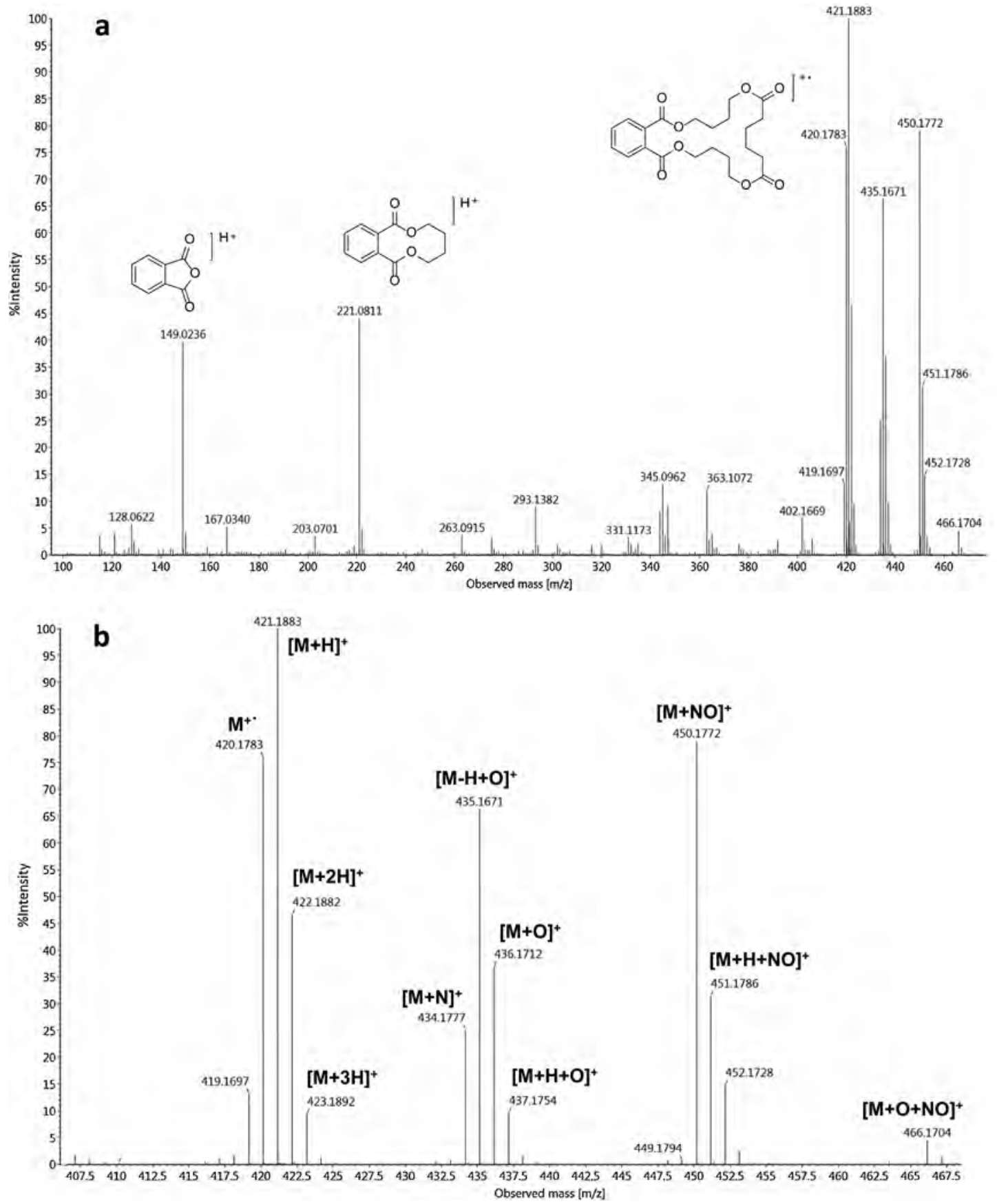

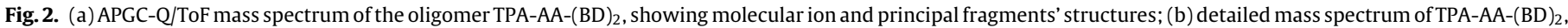
highlighting adduct ions.

established in order to assure that there is no health risk for the consumer. TTC values for Class I, II and III are $30,9.0$ and $1.5 \mathrm{mg} \mathrm{kg}^{-1}$ bw/day [55]. Assuming an average bodyweight of $60 \mathrm{~kg}$ and a daily consumption of $1 \mathrm{~kg}$ food that has been in contact with the packaging, the maximum migration values to assure consumers health would be $1.8,0.54$ and $0.09 \mathrm{mg} \mathrm{kg}^{-1}$ (for Class I, II and III, respectively). The results showed migration values above these limits for many volatiles after the first use of this material.

The four compounds presenting the highest concentration after migration were 2-acetyl-2,3,5,6-tetrahydro-1,4-thiazine (M1), 4-hydroxy-3,5-dimethyl-2-furanone (M2), tetradecanoic acid, hexadecyl ester (M3) and hexadecanoic acid, hexadecyl ester (M4). The concentration of these compounds was plotted for three consecutive experiments simulating repeated use (Fig. 3 ). The results showed that the migration of volatile NIAS decreased with the repeated use of this material, being $31.08 \pm 0.97,27.31 \pm 1.63$, $18.76 \pm 0.95$ and $14.92 \pm 0.61 \mathrm{mg} \mathrm{kg}^{-1}$. the maximum concentration found in migration respectively.

\section{Conclusions}

After a strong solvent extraction of the starch-based material, 21 compounds were detected, 14 of which were identified with a certain level of confidence, and four confirmed by standard injection. GC-EI-MS and APGC-Q/ToF systems were demonstrated to be complementary for identifying extractables and leachables. Notably, APGC coupled to high resolution mass spectrometer provides the accurate mass of the molecular ion, not always visible in the EI spec- 


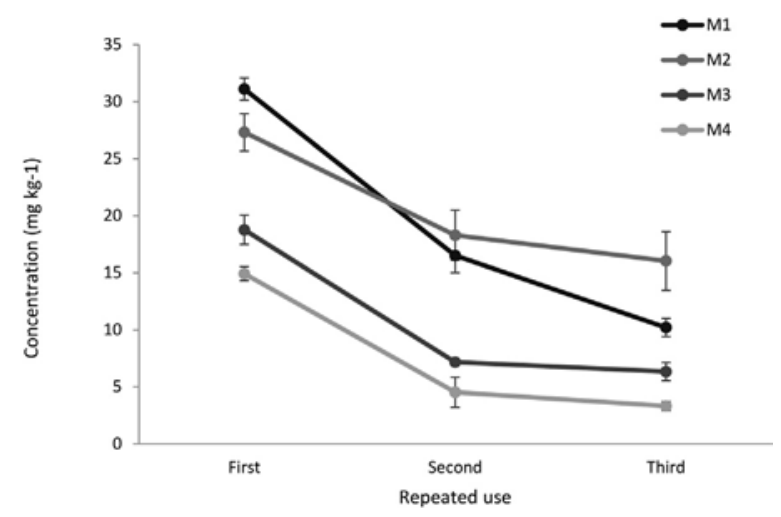

Fig. 3. Repeated migration values for the four compounds presenting the highest concentration in ethanol 95\%: M1 (2-acetyl-2,3,5,6-tetrahydro-1,4-thiazine), M2 (4hydroxy-3,5-dimethyl-2-furanone), M3 (tetradecanoic acid hexadecyl ester), and M4 (hexadecanoic acid, hexadecyl ester).

trum, as well as its fragments and adducts formed at the GC-MS interface. APGC-Q/ToF has shown to be an extremely useful tool in the process of NIAS identification and therefore and its use will help to determine potential migrants from food contact materials and improve its risk assessment. In this work, for the first time the recent advances in APGC ionization pathways were applied to the structure elucidation of unknown compounds coming from a novel biopolymer. The results showed that a range of compounds were intentionally added to the polymer as lubricants, plasticizers, slip agents, and antioxidants. Among NIAS, three oligomers were identified. Specific migration in ethanol 95\% (v/v) showed migration values above those recommended according to the TTC approach, suggesting a re-formulation of the material to be needed if being employed to contain foods with a lipophilic character. Further investigations on the non-volatile leachable fraction and a toxicological study on the major migrant components should also be addressed to ensure the safety of consumers.

\section{Acknowledgements}

The authors acknowledge Projects AGL2015-67362-P from MINECO (Spain) and FEDER funds and Project RYC-2012-11856 (Ramón y Cajal Research Program). The authors thank the Aragon Government and European Social Funds for the financial help given to GUIA group T-10. The authors also thank Waters Corporation for technical support.

\section{Appendix A. Supplementary data}

Supplementary material related to this article can be found, in the online version, at doi:https://doi.org/10.1016/j.chroma.2019. 04.007.

\section{References}

[1] J. Muller, C. González-Martínez, A. Chiralt, Combination of poly(lactic) acid and starch for biodegradable food packaging, Materials (Basel) 10 (2017) 1-22, http://dx.doi.org/10.3390/ma10080952.

[2] E. Canellas, P. Vera, C. Nerín, Risk assessment derived from migrants identified in several adhesives commonly used in food contact materials, Food Chem. Toxicol. 75 (2015) 79-87, http://dx.doi.org/10.1016/j.fct.2014.10.029.

[3] C. Nerín, M. Wrona, Polymers/Food Contact and Packaging Materials-Analytical Aspects, 3rd ed., Elsevier Inc., 2018, http://dx.doi.org/ 10.1016/b978-0-12-409547-2.14012-0.

[4] O. Vilpoux, L. Averous, Starch-based plastics, in: Starches - Charact. Prop. Appl., 2010, pp. 103-128, http://dx.doi.org/10.1201/9781420080247-c6.

[5] D. Lourdin, G. Della Valle, P. Colonna, D. Poussin, Polymères biodégradables. Mise en oeuvre et propriétés de l'amidon, Caoutch. Plast. 780 (1999) 39-42.

[6] R.J.B. Peters, I. Groeneveld, P.L. Sanchez, W. Gebbink, A. Gersen, M. de Nijs, S.P.J. van Leeuwen, Review of analytical approaches for the identification of non-intentionally added substances in paper and board food contact materials, Trends Food Sci. Technol. 85 (2019) 44-54, http://dx.doi.org/10. 1016/j.tifs.2018.12.010.

[7] G. Andaluri, M. Manickavachagam, R. Suri, Plastic toys as a source of exposure to bisphenol-A and phthalates at childcare facilities, Environ. Monit. Assess. 190 (2018), http://dx.doi.org/10.1007/s10661-017-6438-9.

[8] M. Galonnier, P. Murat, S. Cosledan, F. Pierre-Jacques, V. Simon, Safety evaluation of the migration in oily cosmetic products in contact with plastic packagings, Toxicol. Lett. 295 (2018) S165, http://dx.doi.org/10.1016/j.toxlet 2018.06.790.

[9] C. Nerin, J.L. Ubeda, P. Alfaro, Y. Dahmani, M. Aznar, E. Canellas, R. Ausejo, Compounds from multilayer plastic bags cause reproductive failures in artificial insemination, Sci. Rep. 4 (2014) 1-10, http://dx.doi.org/10.1038/ srep04913.

[10] N. Szczepańska, B. Kudłak, J. Namieśnik, Recent advances in assessing xenobiotics migrating from packaging material - a review, Anal. Chim. Acta 1023 (2018) 1-21, http://dx.doi.org/10.1016/j.aca.2018.03.045.

[11] N. Szczepańska, B. Kudłak, S. Tsakovski, G. Yotova, M. Nedyalkova, V. Simeonov, A. Dołęga, J. Namieśnik, Modeling and MANOVA studies on toxicity and endocrine potential of packaging materials exposed to different extraction schemes, Environ. Res. 165 (2018) 294-305, http://dx.doi.org/10. 1016/j.envres.2018.05.004.

[12] M. Aznar, S. Ubeda, N. Dreolin, C. Nerín, Determination of non-volatile components of a biodegradable food packaging material based on polyester and polylactic acid (PLA) and its migration to food simulants, J. Chromatogr. A (2018), http://dx.doi.org/10.1016/j.chroma.2018.10.055.

[13] M. Biedermann, K. Grob, Advantages of comprehensive two-dimensional gas chromatography for comprehensive analysis of potential migrants from food contact materials, Anal. Chim. Acta 1057 (2018) 11-17, http://dx.doi.org/10. 1016/j.aca.2018.10.046

[14] V. García Ibarra, A. Rodríguez Bernaldo de Quirós, P. Paseiro Losada, R. Sendón, Identification of intentionally and non-intentionally added substances in plastic packaging materials and their migration into food products, Anal. Bioanal. Chem. 410 (2018) 3789-3803, http://dx.doi.org/10. 1007/s00216-018-1058-y.

[15] A. Rodríguez Rojas, A. Arango Ospina, P. Rodríguez Vélez, R. Arana Flãrez, ¿What is the new about food packaging material? A bibliometric review during 1996-2016, Trends Food Sci. Technol. 85 (2019) 252-261, http://dx. doi.org/10.1016/j.tifs.2019.01.016.

[16] C. Wang, W. Gao, Y. Liang, Y. Jiang, Y. Wang, Q. Zhang, G. Jiang, Migration of chlorinated paraffins from plastic food packaging into food simulants: concentrations and differences in congener profiles, Chemosphere 225 (2019) 557-564, http://dx.doi.org/10.1016/j.chemosphere.2019.03.039.

[17] S. Noureddine El Moussawi, R. Ouaini, J. Matta, H. Chébib, M. Cladière, V. Camel, Simultaneous migration of bisphenol compounds and trace metals in canned vegetable food, Food Chem. 288 (2019) 228-238, http://dx.doi.org/10. 1016/j.foodchem.2019.02.116.

[18] Z. Cheng, X. Zhang, X. Geng, K.L. Organtini, F. Dong, J. Xu, X. Liu, X. Wu, Y. Zheng, A target screening method for detection of organic pollutants in fruits and vegetables by atmospheric pressure gas chromatography quadrupole-time-of-flight mass spectrometry combined with informatics platform, J. Chromatogr. A 1577 (2018) 82-91, http://dx.doi.org/10.1016/j. chroma.2018.09.043.

[19] European Commission, Commission Regulation (EU) No 10/2011 of 14 January 2011 on plastic materials and articles intended to come into contact with food, Off. J. Eur. Commun. 50 (2011) 1-89, 2011.

[20] C. Nerin, P. Alfaro, M. Aznar, C. Domeño, The challenge of identifying non-intentionally added substances from food packaging materials: a review, Anal. Chim. Acta 775 (2013) 14-24, http://dx.doi.org/10.1016/j.aca.2013.02. 028 .

[21] O.G. Piringer, A.L. Baner, Plastic Packaging Materials for Food, New York, 2000, http://dx.doi.org/10.1002/9783527613281, 596.

[22] J.S. Félix, F. Isella, O. Bosetti, C. Nerín, Analytical tools for identification of non-intentionally added substances (NIAS) coming from polyurethane adhesives in multilayer packaging materials and their migration into food simulants, Anal. Bioanal. Chem. 403 (2012) 2869-2882, http://dx.doi.org/10. 1007/s00216-012-5965-z.

[23] P. Vera, E. Canellas, C. Nerín, Migration of odorous compounds from adhesives used in market samples of food packaging materials by chromatography olfactometry and mass spectrometry (GC-O-MS), Food Chem. 145 (2014) 237-244, http://dx.doi.org/10.1016/j.foodchem.2013.06.087.

[24] J. Wagner, L. Castle, P.K.T. Oldring, T. Moschakis, B.L. Wedzicha, Factors affecting migration kinetics from a generic epoxy-phenolic food can coating system, Food Res. Int. 106 (2018) 183-192, http://dx.doi.org/10.1016/j. foodres.2017.12.059.

[25] Y. Zhang, Y. Chen, R. Li, W. Chen, Y. Song, D. Hu, Z. Cai, Determination of PM2.5-bound polyaromatic hydrocarbons and their hydroxylated derivatives by atmospheric pressure gas chromatography-tandem mass spectrometry, Talanta 195 (2019) 757-763, http://dx.doi.org/10.1016/j.talanta.2018.12.006.

[26] Z. Cheng, F. Dong, J. Xu, X. Liu, X. Wu, Z. Chen, X. Pan, Y. Zheng, Atmospheric pressure gas chromatography quadrupole-time-of-flight mass spectrometry for simultaneous determination of fifteen organochlorine pesticides in soil and water, J. Chromatogr. A 1435 (2016) 115-124, http://dx.doi.org/10.1016/ j.chroma.2016.01.025.

[27] E. Canellas, P. Vera, C. Domeño, P. Alfaro, C. Nerín, Atmospheric pressure gas chromatography coupled to quadrupole-time of flight mass spectrometry as a 
powerful tool for identification of non intentionally added substances in acrylic adhesives used in food packaging materials, J. Chromatogr. A 1235 (2012) 141-148, http://dx.doi.org/10.1016/j.chroma.2012.02.039.

[28] L. Cherta, T. Portolés, E. Pitarch, J. Beltran, F.J. López, C. Calatayud, B. Company, F. Hernández, Analytical strategy based on the combination of gas chromatography coupled to time-of-flight and hybrid quadrupole time-of-flight mass analyzers for non-target analysis in food packaging, Food Chem. 188 (2015) 301-308, http://dx.doi.org/10.1016/j.foodchem.2015.04 141.

[29] G. ten Dam, I.C. Pussente, G. Scholl, G. Eppe, A. Schaechtele, S. van Leeuwen, The performance of atmospheric pressure gas chromatography-tandem mass spectrometry compared to gas chromatography-high resolution mass spectrometry for the analysis of polychlorinated dioxins and polychlorinated biphenyls in food and feed samples, J. Chromatogr. A 1477 (2016) 76-90, http://dx.doi.org/10.1016/j.chroma.2016.11.035.

[30] M. Aznar, C. Domeño, C. Nerín, O. Bosetti, Set-off of non volatile compounds from printing inks in food packaging materials and the role of lacquers to avoid migration, Dyes Pigm. 114 (2015) 85-92, http://dx.doi.org/10.1016/j. dyepig.2014.10.019.

[31] S. Mohammadi, C. Domeno, I. Nerin, M. Aznar, P. Samper, G. Khayatian, C. Nerin, Toxic compounds from tobacco in placenta samples analyzed by UPLC-QTOF-MS, J. Pharm. Biomed. Anal. 145 (2017) 331-338, http://dx.doi. org/10.1016/j.jpba.2017.06.028.

[32] C. Domeño, E. Canellas, P. Alfaro, A. Rodriguez-Lafuente, C. Nerin, Atmospheric pressure gas chromatography with quadrupole time of flight mass spectrometry for simultaneous detection and quantification of polycyclic aromatic hydrocarbons and nitro-polycyclic aromatic hydrocarbons in mosses, J Chromatogr A 1252 (2012) 146-154, http://dx.doi. org/10.1016/j.chroma.2012.06.061.

[33] K.S. Hasheminasab, A.R. Fakhari, M.H. Koruni, Development of carbon-nanotube-assisted electromembrane extraction in the two-phase mode combined with GC for the determination of basic drugs, J. Sep. Sci. 37 (2014) 85-91, http://dx.doi.org/10.1002/jssc.201300480.

[34] T. Portolés, J.V. Sancho, F. Hernández, A. Newton, P. Hancock, Potential of atmospheric pressure chemical ionization source in GC-QTOF MS for pesticide residue analysis, J. Mass Spectrom. 45 (2010) 926-936, http://dx.doi.org/10. $1002 /$ jms. 1784

[35] C. Jin, J. Viidanoja, M. Li, Y. Zhang, E. Ikonen, A. Root, M. Romanczyk, J. Manheim, E. Dziekonski, H.I. Kenttämaa, Comparison of atmospheric pressure chemical ionization and field ionization mass spectrometry for the analysis of large saturated hydrocarbons, Anal. Chem. 88 (2016) 10592-10598, http://dx. doi.org/10.1021/acs.analchem.6b02789.

[36] N. Hourani, N. Kuhnert, High molecular weight non-polar hydrocarbons as pure model substances and in motor oil samples can be ionized without fragmentation by atmospheric pressure chemical ionization mass spectrometry, Rapid Commun. Mass Spectrom. 26 (2012) 2365-2371, http:/ dx.doi.org/10.1002/rcm.6338.

[37] S.T. Ayrton, R. Jones, D.S. Douce, M.R. Morris, R.G. Cooks, Uncatalyzed, regioselective oxidation of saturated hydrocarbons in an ambient coron discharge, Angew. Chemie - Int. Ed. 57 (2018) 769-773, http://dx.doi.org/10 1002/anie.201711190.

[38] B. Li, Z.W. Wang, Q.B. Lin, C.Y. Hu, Simultaneous determination of antioxidants and ultraviolet stabilizers in polypropylene food packaging and food simulants by high-performance liquid chromatography, Acta Chromatogr. 29 (2017) 173-192, http://dx.doi.org/10.1556/1326.2017.29.2.03

[39] A. Yehia, A. Mizuno, Suppression of the ozone generation in the positive and negative dc corona discharges, Int. J. Plasma Environ. Sci. Technol. 2 (2008) 44-49.

[40] I. Dzidic, D.I. Carroll, R.N. Stillwell, C.E. Horning, Comparison of positive ions formed in nickel-63 and corona discharge ion sources using nitrogen, argon, isobutane, ammonia and nitric oxide as reagents in atmospheric pressure ionization mass spectrometry, Anal. Chem. 48 (1976) 1763-1768.
[41] M.G. Pintado-Herrera, E. González-Mazo, P.A. Lara-Martín, Atmospheric pressure gas chromatography-time-of-flight-mass spectrometry (APGC-ToF-MS) for the determination of regulated and emerging contaminants in aqueous samples after stir bar sorptive extraction (SBSE) Anal. Chim. Acta 851 (2014) 1-13, http://dx.doi.org/10.1016/j.aca.2014.05. 030.

[42] N.A. Porter, S.E. Caldwell, K.A. Mills, Mechanisms of free radical oxidation of unsaturated lipids, Lipids 30 (1995) 61-78, http://dx.doi.org/10.4324/ 9780203846704

[43] S. Caillé, J.M. Salmon, N. Bouvier, A. Roland, A. Samson, Modification of the olfactory sensory characteristics of Chardonnay wine through the increase in sotolon concentration, Food Qual. Prefer. 56 (2017) 225-230, http://dx.doi. org/10.1016/j.foodqual.2016.08.001.

[44] V. Ferreira, I. Jarauta, R. López, J. Cacho, Quantitative determination of sotolon, maltol and free furaneol in wine by solid-phase extraction and gas chromatography-ion-trap mass spectrometry, J. Chromatogr. A 1010 (2003) 95-103, http://dx.doi.org/10.1016/S0021-9673(03)00963-4.

[45] M. Watanabe, C. Nakata, W. Wu, K. Kawamoto, Y. Noma, Characterization of semi-volatile organic compounds emitted during heating of nitrogen-containing plastics at low temperature, Chemosphere 68 (2007) 2063-2072, http://dx.doi.org/10.1016/j.chemosphere.2007.02.022.

[46] P. Schieberle, New developments in methods for analysis of volatile compounds and their precursors, Charact. Food Emerg. Methods (1995) 403-431, http://dx.doi.org/10.1016/B978-044481499-9/50018-4.

[47] P. Vera, E. Canellas, C. Nerín, Identification of non volatile migrant compounds and NIAS in polypropylene films used as food packaging characterized by UPLC-MS/QTOF, Talanta 188 (2018) 750-762, http://dx.doi.org/10.1016/j. talanta.2018.06.022.

[48] G. Lv, L. Wang, J. Liu, S. Li, Method for determination of fatty acid amides in polyethylene packaging materials-Gas chromatography/mass spectrometry, J Chromatogr. A 1216 (2009) 8545-8548, http://dx.doi.org/10.1016/j.chroma. 2009.10.008

[49] M.J. Silva, E. Samandar, X. Ye, A.M. Calafat, In vitro metabolites of Di-2-ethylhexyl adipate (DEHA) as biomarkers of exposure in human biomonitoring applications, Chem. Res. Toxicol. 26 (2013) 1498-1502, http:// dx.doi.org/10.1021/tx400215z.

[50] E. Canellas, P. Vera, C. Nerín, UPLC-ESI-Q-TOF-MS(E) and GC-MS identification and quantification of non-intentionally added substances coming from biodegradable food packaging, Anal. Bioanal. Chem. 407 (2015) 6781-6790, http://dx.doi.org/10.1007/s00216-015-8848-2.

[51] J.B. Olivato, M.V.E. Grossmann, A.P. Bilck, F. Yamashita, Effect of organic acids as additives on the performance of thermoplastic starch/polyester blown films, Carbohydr. Polym. 90 (2012) 159-164, http://dx.doi.org/10.1016/j. carbpol.2012.05.009.

[52] G. Bheemaneni, S. Saravana, R. Kandaswamy, Processing and Characterization of Poly (butylene adipate-co-terephthalate)/ Wollastonite Biocomposites for Medical Applications, Mater. Today Proc. 5 (2018) 1807-1816, http://dx.doi. $\operatorname{org} / 10.1016 /$ j.matpr.2017.11.279.

[53] I. Skjevrak, C. Brede, I.L. Steffensen, A. Mikalsen, J. Alexander, P. Fjeldal, H. Herikstad, Non-targeted multi-component analytical surveillance of plastic food contact materials: identification of substances not included in EU positive lists and their risk assessment, Food Addit. Contam. 22 (2005) 1012-1022, http://dx.doi.org/10.1080/02652030500090877.

[54] I. Dewhurst, A.G. Renwick, Evaluation of the Threshold of Toxicological Concern (TTC) - Challenges and approaches, Regul. Toxicol. Pharmacol. 65 (2013) 168-177, http://dx.doi.org/10.1016/j.yrtph.2012.03.007.

[55] EFSA, Scientific opinion on exploring options for providing advice about possible human health risks based on the concept of Threshold of Toxicological Concern (TTC), EFSA J. 10 (2012) 2750, http://dx.doi.org/10. 2903/j.efsa.2012.2750. 